\title{
Gender-Specific Independent and Combined Effects of the Progesterone and 17-Hydroxyprogesterone on Metabolic Syndrome: From the Henan Rural Cohort Study
}

\author{
Mian Wang ${ }^{1} * *$ \\ Luting $\mathrm{Nie}^{1, *}$ \\ Dandan $\mathrm{Wei}^{2}$ \\ Pengling Liu $^{2}$ \\ Li Zhang ${ }^{2}$ \\ Keliang Fan $^{2}$ \\ Yu Song' \\ Lulu Wang ${ }^{2}$ \\ Qingqing $X u^{2}$ \\ Juan Wang ${ }^{2}$ \\ Xiaotian Liu $^{2}$ \\ Linlin $\mathrm{Li}^{2}$ \\ Zhenxing $\mathrm{Mao}^{2}$ \\ Chongjian Wang (D) ${ }^{2}$ \\ Wenqian Huo (D) \\ 'Department of Occupational and \\ Environmental Health, College of Public \\ Health, Zhengzhou University, \\ Zhengzhou, Henan, People's Republic of \\ China; ${ }^{2}$ Department of Epidemiology and \\ Biostatistics, College of Public Health, \\ Zhengzhou University, Zhengzhou, \\ Henan, People's Republic of China \\ *These authors contributed equally to \\ this work
}

Correspondence: Wenqian Huo Department of Occupational and Environmental Health Sciences, College of Public Health, Zhengzhou University, 100 Kexue Avenue, Zhengzhou, 45000I,

Henan, People's Republic of China

Tel $+8637|6778| 452$

Fax +86 37I 67781868

Email huowenqian@zzu.edu.cn
Background: Although the concentrations of progesterone (P4) and 17hydroxyprogesterone (17-OHP) have been correlated with some characteristics of metabolic syndrome (MetS), the relationships with MetS are inconclusive. Therefore, we investigated the relationship between P4 and 17-OHP with MetS.

Methods: In all, the present study includes 4807 participants. Serum P4 and 17-OHP were measured through liquid chromatography-tandem mass spectrometry. Logistic regression and restricted cubic splines were used to assess the independent and combined effects of P4 and 17-OHP on MetS.

Results: After adjusting for multiple variables, the positive association of $\mathrm{P} 4$ with MetS was observed in postmenopausal women (Third tertiles vs First tertiles: OR $=1.49,95 \%$ CI: 1.20 $1.86)$ and the negative association of 17-OHP with MetS was observed in men (Third tertiles vs First tertiles: $\mathrm{OR}=0.43,95 \% \mathrm{CI}: 0.32-0.58$ ). Compared with the combination of low $\mathrm{P} 4$ and low 17-OHP, the combination of high $\mathrm{P} 4$ and high 17-OHP were significantly related to MetS in postmenopausal women $(\mathrm{OR}=1.71,95 \% \mathrm{CI}: 1.18-2.48)$. Moreover, the combination of low P4 and high 17-OHP was negatively associated with MetS in men (OR $=0.41,95 \%$ CI: 0.24-0.69). Conclusion: The association between $\mathrm{P} 4$ and MetS in postmenopausal women was positive, whereas 17-OHP was negatively associated with MetS in men. Additionally, their combination has a synergistic effect on MetS in postmenopausal women and an antagonistic effect on MetS in men. Keywords: progesterone, 17-hydroxyprogesterone, metabolic syndrome, obesity

\section{Introduction}

Non-communicable diseases are the leading causes of death globally. ${ }^{1}$ Metabolic syndrome (MetS) is the most common non-communicable disease, which comprises a group characterized by obesity, insulin (INS) resistance, hypertension (HTN), and hyperlipidemia (HD). ${ }^{1}$ The prevalence of MetS is $33.9 \%$ among Chinese adults ${ }^{2}$ and MetS may facilitate the development of diseases, including non-alcoholic steatohepatitis, cardiovascular disease, type 2 diabetes mellitus (T2DM), and cancer. ${ }^{3,4}$ Thus, it is of significant priority to improve the understanding of the pathological mechanisms in order to develop powerful strategies to counter the treatment and prevention of the MetS.

Progesterone (P4) and 17-hydroxyprogesterone (17-OHP) are produced by the gonads and adrenal origin and $\mathrm{P} 4$ is concerned with regulating a variety of 
physiological processes containing reproductive, immune and neurological functions. The P4 made from gonads perform their biological functions mainly in the blood, while those produced by the adrenal glands are converted primarily for glucocorticoids and androgens. 17-OHP is a C21 steroid generated by P4 via 17-hydroxylase or 17hydroxypregnenolone via $3 \beta$-hydroxysteroid dehydrogenase/ $\Delta 5-4$ isomerase and play an intermediate role in the biosynthesis of hydrocortisone and gonadal steroid hormones. ${ }^{5}$ The concentration of 17-OHP is widely used for neonatal congenital adrenal hyperplasia screening because it is a sensitive indicator of 21-hydroxylase deficiency. Moreover, most circulating 17-OHP in men may come from the testes rather than the adrenal glands, as studies have found that orchiectomy reduces circulating 17-OHP levels by approximately $70 \%{ }^{6,7}$

Recently, many studies have been performed to prove that the concentration of P4 and 17-OHP were associated with metabolic diseases. A study found significantly elevated levels of P4 is present in diabetic and obese $\mathrm{db} / \mathrm{db}$ mice. ${ }^{8}$ Increased $\mathrm{P} 4$ concentrations in blood during the luteal phase were observed in another animal study using young Ossabaw pigs fed a high-fructose, high-fat, high-cholesterol diet for a short-term to simulate obese women. ${ }^{9}$ Our previous study found that prediabetes and T2DM have a positive association with the concentration of serum P4 and negatively associated with the concentration of serum pregnenolone in rural Chinese men and postmenopausal women. ${ }^{10}$ Additionally, Nina ${ }^{11}$ has shown that estrogen and $\mathrm{P} 4$ have essential implications on cardiovascular function and humoral regulation. Both reproductive hormones affect the blood pressure response to sodium load. Meanwhile, another study observed that lower 17-OHP concentrations in hypertensive patients than in normotensive individuals. ${ }^{12}$ On the other hand, a P4 and glucocorticoid antagonist, mifepristone, under investigation for Cushing's syndrome therapy, significantly reduces high-density lipoprotein cholesterol (HDL-c), high-density lipoprotein (HDL), total cholesterol and apoA-I particle concentrations in healthy postmenopausal women. ${ }^{13}$ However, no study has estimated the associations of P4 and 17-OHP with MetS, much less their combined effect on the MetS.

Consequently, it is crucial and urgent to explore the relationships of $\mathrm{P} 4,17-\mathrm{OHP}$ and their combination effect with MetS. So, we investigated the relationship of P4, 17OHP and their combination effect with MetS in China's rural residents of Henan Province. The present study was designed to examine (1) the effect of P4 and 17-OHP on MetS, (2) the latent effects of gender on this relationship, and (3) the combined influences of P4 and 17-OHP on MetS among the rural population.

\section{Materials and Methods Study Population}

All the data in the present study were taken from the baseline data in the Henan Rural Cohort Study, which is an ongoing prospective observational study aimed to investigate the potential risk factors of common chronic diseases in the Chinese rural population. ${ }^{14}$ All of the 6670 participants were enrolled through a multi-stage, stratified cluster sampling method. Participants' information was collected by trained public health workers and physicians using a standardized questionnaire. The content mainly consisted of demographic characteristics (gender, age, average monthly income as well as education levels), lifestyle habits (physical activity and drinking, smoking status), and personal or family histories of chronic diseases (eg, HD, HTN, and diabetes). Anthropometric measurements (eg, waist, hip circumference and, height and weight) were collected based on standard methods by trained study staff. Three times measurements on the right arm at sitting position using electronic sphygmomanometers (Omron HEM-7071A, Japan) to collect the resting blood pressure. Educational attainment was divided into illiteracy, primary school, junior middle school or above groups and average monthly income was divided into less than 500 RMB, 500-999 RMB, no less than 1000 RMB groups. Smoking and drinking status were divided into current, former/never groups, respectively. Physical activity was categorized into three groups: low, mediate and high level according to the International Physical Activity Questionnaire (IPAQ). ${ }^{15}$

A total of 4807 participants were finally included in this study, of which 1049 participants were with MetS, 3758 were non-MetS participants. Men and postmenopausal women aged 18 to 79 years were enrolled in the present study. Participants who missed the data of serum samples $(\mathrm{n}=410)$, MetS $(\mathrm{n}=10)$, body mass index (BMI) $(\mathrm{n}=10)$, systolic blood pressure $(n=1)$, triglyceride $(\mathrm{TG})(\mathrm{n}=14)$, INS $(n=30)$, fasting plasma glucose $(\mathrm{FPG})(\mathrm{n}=3)$ and other key covariates $(n=2)$ were excluded. Among women participants, those who were not yet menopausal $(n=1329)$, those with missing data on menopause $(n=19)$, and those taking contraceptive pills $(n=27)$ were excluded because of the significant influence of the menstrual cycle and contraceptives on the concentration of progestogen. Women 
smokers were also excluded $(n=8)$. The study and its protocols were approved by the Zhengzhou University Life Science Ethics Committee and conducted in compliance with the principles of the Declaration of Helsinki. Ethics approval code: [2015] MEC(S128). All participants were informed of the purpose and nature of all procedures used and provided written informed consent.

\section{Laboratory Measurements}

The venous blood samples of participants were collected after overnight fasting. After centrifugation at $3000 \mathrm{rpm}$ at $4^{\circ} \mathrm{C}$ for $10 \mathrm{~min}$, the serum was separated and extracted and then stored at $-80^{\circ} \mathrm{C}$. The concentration of total cholesterol (TC), TG, FPG, low-density lipoprotein cholesterol (LDLc), and HDL-c was measured using an automatic biochemical analyzer (Roche Cobas C501). HbAlc was assayed using the HPLC method (Bio-Rad VARIANT II). INS $\beta$ cell function and resistance with the corresponding indexes were estimated with the updated homeostasis model.

The serum level of P4 and 17-OHP was measured with the liquid chromatography-tandem mass spectrometry method (Waters e2695, Waters XEVO TQ-S system, Waters), blinded to MetS and non-MetS status. ${ }^{16,17}$ The limits of detection and quantification of P4 were $0.02 \mathrm{ng} /$ $\mathrm{mL}$ and $0.05 \mathrm{ng} / \mathrm{mL}$ and the limits of detection and quantification were $0.2 \mathrm{ng} / \mathrm{mL}$ and $0.5 \mathrm{ng} / \mathrm{mL}$ for $17-\mathrm{OHP}$. See Supplementary Table 1 for a detailed description of the detection methods.

\section{Definition of MetS}

The MetS was defined using the International Diabetes Federation (IDF) criteria. ${ }^{18}$ Participants with a waist circumference (WC) $\geq 90 \mathrm{~cm}$ for men or $\geq 80 \mathrm{~cm}$ for women and presented with two or more of the following risk factors was defined as MetS: (1) TG no less than 1.7 $\mathrm{mmol} / \mathrm{L}$; (2) HDL-c less than $1.04 \mathrm{mmol} / \mathrm{L}$ for men and less than $1.3 \mathrm{mmol} / \mathrm{L}$ for women; (3) FPG level no less than $5.6 \mathrm{mmol} / \mathrm{L}$ or use of anti-diabetic medicine; (4) blood pressure no less than $130 \mathrm{mmHg} / 85 \mathrm{mmHg}$ or use of antihypertensive medicine.

\section{Statistical Analysis}

Normal and non-normal distributions of continuous variables were expressed as mean (standard deviation, SD) and categorical variables were defined as numbers (percentages). The statistical differences between groups were performed by chi-square tests (categorical variables) or Student's $t$-test (continuous variables).
Before conducting the analysis, $\mathrm{P} 4$ and 17-OHP were defined as $\ln -\mathrm{P} 4$ and $\ln -17-\mathrm{OHP}$ after natural logtransformed due to the skewed distribution of serum P4 and 17-OHP levels. To examine the effect on MetS, this study divided P4 and 17-OHP into three groups and the lowest tertile groups as reference. Independent analyses were made in men and women to explore the possible gender specificity. Odds ratios (ORs) were estimated by Logistic regression with $95 \%$ CIs for MetS by continuous P4 and 17-OHP and tertiles of P4 and 17-OHP. Multivariable adjusted models are as follows:

Model 1: no adjustment

Model 2: gender, age, marriage status, culture, smoking habit, drinking habit, average monthly income, high fat diet, physical activity, more vegetables and fruits intake

Model 3: as in model 2, plus a family history of HTN, HD, TD

Moreover, trend tests were utilized to assess the doseresponse relationships by performed tertiles as continuous variables. The presence of non-linear dose-response relationships between continuous $\mathrm{P} 4$ and 17-OHP with MetS were accessed by restricted cubic splines, with three knots specified at 25th, 50th, 75th and 30th, 60th, 90th percentiles, respectively; $0.435 \mathrm{ng} / \mathrm{mL}$ and $0.1 \mathrm{ng} / \mathrm{mL}$ were taken as the reference for P4 and 17-OHP based on their distribution. Considering that hormone replacement therapy might affect serum P4 and 17-OHP levels among women, sensitivity analyses were conducted by excluding participants taking hormone replacement to assess the robustness of the effect estimations.

The combined effects of P4 and 17-OHP on MetS were performed by logistic regression analysis based on model 3 and comprising the terms of the corresponding tertiles, OR were calculated using the lowest tertiles of $\mathrm{P} 4$ and the lowest tertiles of 17-OHP as reference. ${ }^{19}$ Statistics were performed with SPSS statistical software (SPSS, version 21.0; SPSS Inc., Chicago, IL, USA). $P<0.05$ was considered to be statistically significant.

\section{Results}

\section{Characteristics of Participants}

In total, 4807 participants $(52.9 \%$ for men, $47.1 \%$ for women) with a mean age of 59.36 were enrolled in the present study, and the prevalence of MetS was $21.8 \%$. Characteristics of participants based on MetS status are shown in Table 1. The participants with MetS had significantly higher levels of $\mathrm{P} 4$, WC, weight, BMI, diastolic 
Table I Characteristics of the Participants

\begin{tabular}{|c|c|c|c|}
\hline \multirow[t]{2}{*}{ Variables } & \multirow{2}{*}{$\begin{array}{l}\text { Non-MetS } \\
N=3758\end{array}$} & \multirow{2}{*}{$\begin{array}{l}\text { MetS } \\
N=1049\end{array}$} & \multirow[t]{2}{*}{$P^{a}$ value } \\
\hline & & & \\
\hline Age(years), mean $\pm S D$ & $59.43 \pm 9.91$ & $59.09 \pm 9.18$ & 0.299 \\
\hline $\begin{array}{l}\text { Sex, n (\%) } \\
\text { Men } \\
\text { Women }\end{array}$ & $\begin{array}{l}2195(58.4) \\
1563(41.6)\end{array}$ & $\begin{array}{l}348(33.2) \\
70 I(66.8)\end{array}$ & $<0.001$ \\
\hline $\begin{array}{l}\text { Culture, n (\%) } \\
\text { Illiteracy } \\
\text { Primary school } \\
\geq \text { Junior middle school }\end{array}$ & $\begin{array}{l}744(19.8) \\
1068(28.4) \\
1946(51.8)\end{array}$ & $\begin{array}{l}225(21.4) \\
292(27.8) \\
532(50.7)\end{array}$ & 0.499 \\
\hline $\begin{array}{l}\text { Marriage status, } \mathrm{n}(\%) \\
\text { Married/cohabitation } \\
\text { Divorced/widowed/unmarried }\end{array}$ & $\begin{array}{l}3304(87.9) \\
454(12.1)\end{array}$ & $\begin{array}{l}944(90) \\
105(10)\end{array}$ & 0.064 \\
\hline $\begin{array}{l}\text { Income, } n(\%) \\
\quad<500 \text { RMB } \\
\text { 500-999RMB } \\
\geq 1000 \text { RMB }\end{array}$ & $\begin{array}{l}1328(35.3) \\
1068(28.4) \\
1362(36.2)\end{array}$ & $\begin{array}{l}331(31.6) \\
296(28.2) \\
422(40.2)\end{array}$ & 0.031 \\
\hline Family history of HTN, n (\%) & $526(14)$ & $259(24.7)$ & $<0.001$ \\
\hline Family history of HD, n (\%) & $110(2.9)$ & $60(5.7)$ & $<0.001$ \\
\hline Family history of T2DM, n (\%) & $68(1.8)$ & $2 I(2)$ & 0.683 \\
\hline $\begin{array}{l}\text { Physical activity, n (\%) } \\
\text { Low } \\
\text { Moderate } \\
\text { High }\end{array}$ & $\begin{array}{l}837(22.3) \\
1749(46.5) \\
1172(31.2)\end{array}$ & $\begin{array}{l}250(23.8) \\
562(53.6) \\
237(22.6)\end{array}$ & $<0.001$ \\
\hline More vegetable and fruit intake, $\mathrm{n}(\%)$ & $2455(65.3)$ & $713(68)$ & 0.11 \\
\hline High-fat diet, n (\%) & $957(25.5)$ & $267(25.5)$ & 0.993 \\
\hline Current smoker, n (\%) & $1042(27.7)$ & $152(14.5)$ & $<0.001$ \\
\hline Current drinker, n (\%) & $710(18.9)$ & $177(16.9)$ & 0.136 \\
\hline Height $(\mathrm{cm})$, mean \pm SD & $161.08 \pm 8.46$ & $159.85 \pm 8.38$ & $<0.001$ \\
\hline$W C(\mathrm{~cm})$, mean $\pm S D$ & $80.40 \pm 8.94$ & $92.18 \pm 7.28$ & $<0.001$ \\
\hline Weight $(\mathrm{kg})$, mean \pm SD & $59.52 \pm 9.97$ & $68.36 \pm 10.69$ & $<0.001$ \\
\hline BMI $\left(\mathrm{kg} / \mathrm{m}^{2}\right)$, mean $\pm \mathrm{SD}$ & $22.87 \pm 2.91$ & $26.65 \pm 2.75$ & $<0.001$ \\
\hline $\mathrm{SBP}(\mathrm{mmHg})$, mean $\pm \mathrm{SD}$ & $121.03 \pm 17.58$ & $133.01 \pm 19.12$ & $<0.001$ \\
\hline $\mathrm{DBP}(\mathrm{mmHg})$, mean $\pm \mathrm{SD}$ & $73.68 \pm 10.16$ & $82.03 \pm 10.82$ & $<0.001$ \\
\hline $\mathrm{HDL}-\mathrm{C}(\mathrm{mmol} / \mathrm{mL})$, mean $\pm \mathrm{SD}$ & $1.43 \pm 0.33$ & $1.14 \pm 0.28$ & $<0.001$ \\
\hline $\mathrm{LDL}-\mathrm{C}(\mathrm{mmol} / \mathrm{mL})$, mean $\pm \mathrm{SD}$ & $2.95 \pm 0.76$ & $3.10 \pm 0.85$ & $<0.001$ \\
\hline $\mathrm{TG}(\mathrm{mmol} / \mathrm{mL})$, mean $\pm \mathrm{SD}$ & $1.36 \pm 0.78$ & $2.49 \pm 1.50$ & $<0.001$ \\
\hline $\mathrm{TC}(\mathrm{mmol} / \mathrm{mL})$, mean $\pm \mathrm{SD}$ & $4.60 \pm 0.85$ & $4.85 \pm 0.96$ & $<0.001$ \\
\hline INS (mlU/mL), mean \pm SD & $11.68 \pm 5.03$ & $13.45 \pm 5.79$ & $<0.001$ \\
\hline $\mathrm{FPG}(\mathrm{mmpl} / \mathrm{mL})$, mean $\pm \mathrm{SD}$ & $5.11 \pm 1.00$ & $5.87 \pm 1.77$ & $<0.001$ \\
\hline $\mathrm{P}(\mathrm{ng} / \mathrm{mL})$, mean $\pm \mathrm{SD}$ & $0.94 \pm 1.26$ & $1.02 \pm 1.16$ & 0.060 \\
\hline I7-OHP (ng/mL), mean \pm SD & $0.87 \pm 2.34$ & $0.56 \pm 0.67$ & $<0.001$ \\
\hline
\end{tabular}

Note: ${ }^{a}$ Compared between participants with and without MetS.

Abbreviations: MetS, metabolic syndrome; HTN, hypertension; HD, hyperlipoidemia; T2DM, type 2 diabetes mellitus; SD, standard deviation; WC, waist circumference; BMI, body mass index; SBP, systolic blood pressure; DBP, diastolic blood pressure; HDL-C, high-density lipoprotein cholesterol; LDL-C, low-density lipoprotein cholesterol; TG, triglyceride; TC, total cholesterol; INS, insulin; FPG, fasting plasma glucose; P, progesterone; 17-OHP, I7-hydroxyprogesterone. 
blood pressure, systolic blood pressure, LDL-c, TC, TG, FPG, as well as a higher proportion of family history of HTN and HD than non-MetS. While non-MetS are more likely to have higher height and a higher level of 17-OHP. The distributions are different in gender, income and physical activity between MetS participants and non-MetS participants. No significant differences are observed in age, culture, marriage status, family history of TD, highfat diet, current drinker, more vegetable and fruit intake and the concentration of P4 distribution among MetS participants and non-MetS participants.

\section{The Independent Associations of P4 and I7-OHP with MetS}

Table 2 shows the positive association of P4 with MetS in postmenopausal women. After adjusting multi variables in model 3 , the significance of the finding remains. For which each 1 unit increase in $\ln -\mathrm{P} 4$ was positively associated with MetS $(\mathrm{OR}=1.13,95 \% \mathrm{CI}=1.01-1.26)$ and the tertile 3 of $\ln$ $\mathrm{P} 4$ was also positively correlated with $\mathrm{MetS}(\mathrm{OR}=1.49,95 \%$ $\mathrm{CI}=1.20-1.86)$ versus tertile 1 . The positive association between $\mathrm{P} 4$ and MetS was also observed in men $(\mathrm{OR}=1.19$, $95 \% \mathrm{CI}=1.01-1.40$ ) but the tertile 2 to 3 of $\mathrm{P} 4$ were not observed significant associations with MetS for men. ORs of MetS increased accompanied by the growth of $\mathrm{P} 4$ in postmenopausal women ( $\mathrm{P}$ for overall association $<0.05$, and $\mathrm{P}$ for nonlinearity $>0.05$ ), No significant dose-response was founded in men.
For 17-OHP in men, it showed an inverse correlation with MetS as each 1 unit increase in $\ln -17-\mathrm{OHP}$ was inversely associated with MetS $(\mathrm{OR}=0.75,95 \%=0.67-0.83)$. After adjusting multiple variables in model 3 , the significance remains. The second and third tertiles of 17-OHP were also negatively associated with MetS versus tertile $1(\mathrm{OR}=0.70$, $95 \%=0.54-0.92 ; \mathrm{OR}=0.43,95 \%=0.32-0.58)$. No significant associations between 17-OHP and MetS were observed in postmenopausal women after adjusting multiple variables. The association between 17-OHP with MetS in the adjusted model 3 of men shown a nonlinear dose-response relationship ( $P$ for overall association $<0.05, P$ for nonlinearity $<0.05$ ). Meanwhile, the presence of non-linear dose-response relationships between continuous P4 and 17-OHP with MetS are shown in Supplementary Figure 1.

\section{The Combined Effect of P4 and I7-OHP with MetS}

As shown in Figure 1, the combination of P4 and 17-OHP showed different effects on MetS among men and postmenopausal women. For men in Figure 1A, the highest ORs occurred in the combination of the third tertile of P4 and the first tertile of 17-OHP (OR $=1.38,95 \% \mathrm{CI}=0.90-$ 2.10), whereas the lowest occurred in the combination of the first tertile of P4 and the third tertile of 17-OHP (OR = $0.47,95 \% \mathrm{CI}=0.29-0.76)$. In the third tertile of $17-\mathrm{OHP}$, it showed a protective effect regardless of the level of $\mathrm{P} 4$. In Figure 1B, there was an enhancement effect between $\mathrm{P} 4$

Table 2 Associations of Progesterone and 17-Hydroxyprogesterone with Metabolic Syndrome in Men and Postmenopausal Women

\begin{tabular}{|c|c|c|c|c|c|c|}
\hline & \multicolumn{3}{|c|}{ Progesterone } & \multicolumn{3}{|c|}{ I7-OH Progesterone } \\
\hline & Model I & Model 2 & Model 3 & Model I & Model 2 & Model 3 \\
\hline \multicolumn{7}{|l|}{ Men } \\
\hline Continuous & $1.24(1.06,1.45)^{\mathrm{a}}$ & $1.20(1.02,1.41)^{\mathrm{a}}$ & $1.19(1.01,1.40)^{\mathrm{a}}$ & $0.72(0.65,0.80)^{\mathrm{a}}$ & $0.75(0.67,0.83)^{\mathrm{a}}$ & $0.75(0.67,0.83)^{\mathrm{a}}$ \\
\hline TI & Reference & Reference & Reference & Reference & Reference & Reference \\
\hline $\mathrm{T} 2$ & $0.86(0.65,1.15)$ & $0.8 \mathrm{I}(0.6 \mathrm{I}, \mathrm{I} .09)$ & $0.81(0.60,1.09)$ & $0.66(0.5 \mathrm{I}, 0.86)^{\mathrm{a}}$ & $0.69(0.53,0.91)^{\mathrm{a}}$ & $0.70(0.54,0.92)^{\mathrm{a}}$ \\
\hline T3 & $1.21(0.92,1.58)$ & $1.16(0.88,1.53)$ & $1.14(0.86,1.5 \mathrm{I})$ & $0.40(0.30,0.54)^{\mathrm{a}}$ & $0.43(0.32,0.58)^{a}$ & $0.43(0.32,0.58)^{\mathrm{a}}$ \\
\hline$P$-trend & 0.158 & 0.273 & 0.333 & $<0.001$ & $<0.001$ & $<0.001$ \\
\hline \multicolumn{7}{|c|}{ Postmenopausal Women } \\
\hline Continuous & $1.14(1.02,1.27)^{\mathrm{a}}$ & $1.14(1.02,1.27)^{\mathrm{a}}$ & $1.13(1.01,1.26)^{\mathrm{a}}$ & $1.04(0.95,1.14)$ & $1.04(0.95,1.14)$ & $1.03(0.94,1.13)$ \\
\hline $\mathrm{TI}$ & Reference & Reference & Reference & Reference & Reference & Reference \\
\hline T2 & $0.92(0.74,1.16)$ & $0.91(0.73,1.15)$ & $0.91(0.73,1.15)$ & $0.94(0.76,1.17)$ & $0.95(0.77,1.19)$ & $0.95(0.76,1.19)$ \\
\hline T3 & $1.50(1.21,1.87)^{\mathrm{a}}$ & $1.5 \mathrm{I}(1.21,1.88)^{\mathrm{a}}$ & $1.49(1.20,1.86)^{\mathrm{a}}$ & $1.18(0.96,1.46)$ & $1.19(0.96,1.47)$ & $1.17(0.94,1.45)$ \\
\hline$P$-trend & $<0.001$ & $<0.001$ & $<0.001$ & 0.156 & 0.143 & 0.188 \\
\hline
\end{tabular}

Note: ${ }^{\text {a }} P<0.05$. 

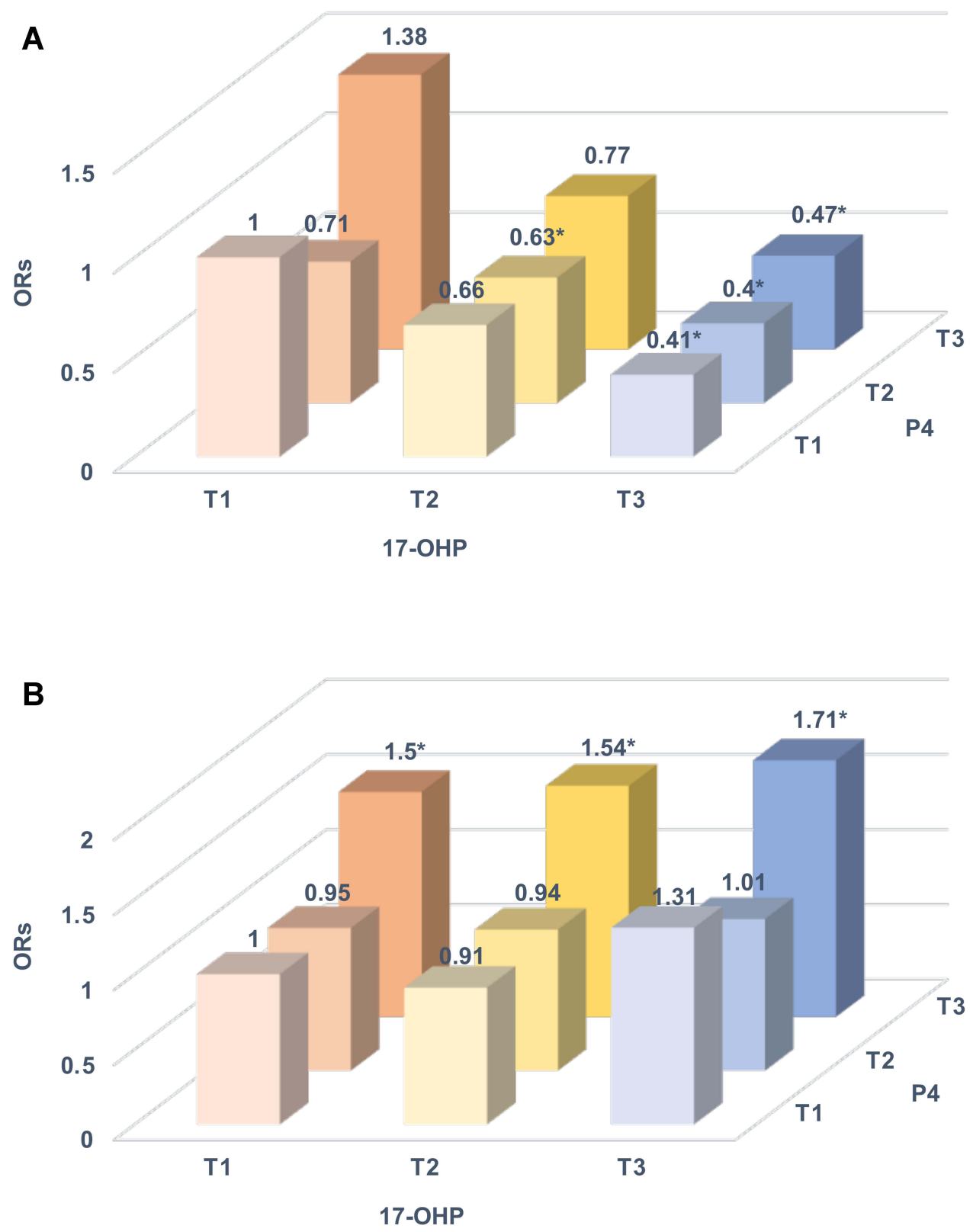

Figure I The effect of progesterone (P4) and 17-hydroxyprogesterone (I7-OHP) combined on metabolic syndrome were analyzed by logistic regression model: (A) men; (B) postmenopausal women. The models were adjusted for age, marriage status, culture, average monthly income, smoking habit, drinking habit, more vegetables and fruits intake, high fat diet, physical activity, and family history of hypertension, hyperlipoidemia, type 2 diabetes mellitus. Three colors and three shades are used to represent the 17-OHP and P4 tertiles, respectively.

Note: $* P<0.05$.

and 17-OHP in postmenopausal women. Compared with the reference, the combination of the third tertile of $\mathrm{P} 4$ and the third tertile of 17-OHP have the highest ORs $(\mathrm{OR}=1.71,95 \% \mathrm{CI}=1.18-2.48)$.

\section{Sensitivity Analyses}

As Supplementary Table 2 and Supplementary Table 3 shown, the independent and combined effects of P4 and 17-OHP on MetS did not change after excluding postmenopausal women who had taken hormone replacement therapy.

\section{Discussion}

Here, we investigated the effect of P4 and 17-OHP on MetS and found a positive association of P4 with MetS and a negative association of 17-OHP with MetS in men. In postmenopausal women, we observed that $\mathrm{P} 4$ was positive with MetS and there were no significant relationships 
between 17-OHP and MetS. Furthermore, the combination of P4 and 17-OHP displayed a synergistic effect on MetS in postmenopausal women. However, an antagonistic effect was observed in men between P4 and 17-OHP.

As far as we know, there no study has investigated the association of P4 with MetS. However, several previous studies of epidemiological have assessed the relationship between P4 and the characters of MetS. Sophie et $\mathrm{al}^{20}$ found increased P4 metabolism in omental adipose tissue of women characterized by abdominal obesity, and they also found that $\mathrm{P} 4$ has an inverse association with $\mathrm{WC}$ in men. ${ }^{21}$ As a critical contributor of MetS, ${ }^{22}$ if there is a strong association between obesity and P4, we can infer that there is also an association between MetS and P4. Consistent with the present study, the results of their studies may speculate that the positive relationship between P4 and MetS in women. However, due to differences in the study population, inference about the results for men may be inconsistent. Our previous study revealed that prediabetes and T2DM are positively associated with the concentration of serum P4 in Chinese rural men and postmenopausal women, ${ }^{10}$ which suggested P4 has a positive relationship with MetS. Nina ${ }^{11}$ found P4 is the prominent steroid that affects blood pressure around menopause. ${ }^{11}$ Likewise, in Peter et $\mathrm{al}^{23}$ reviews, P4 has increased affinity for the mineralocorticoid receptor in Geller syndrome, which could cause enhanced activation of mineralocorticoid signaling cascades that increase $\mathrm{Na}^{+}$ reabsorption and $\mathrm{K}^{+}$secretion. With the increasing concentration of P4 during pregnancy, the risk of HTN is growing either. Thus, there is an inseparable relationship between the concentration of P4 and the occurrence of HTN. What is more, a prospective cohort study that included 40 postmenopausal women suggested that P4 can react vigorously with HDL-c and cause the decrease of HDL-c concentration. ${ }^{24}$ Altogether, due to obesity, INS resistance, HTN and hypercholesterolemia are essential features for diagnosing MetS, and P4 can adversely be associated with these symptoms in postmenopausal women, so we deduce that the concentration of serum P4 has a positive effect on the occurrence of the MetS. This is consistent with the founding of the present study.

On the other hand, the present study also found that 17$\mathrm{OHP}$ has a robust protective effect on MetS in adult men. Olesen et $\mathrm{al}^{25}$ found that the presence of MetS was negatively correlated with 17-OHP, which is consistent with our finds. Moreover, some previous studies have evaluated the relationships between 17-OHP and abnormal characteristics of metabolism. Graeme et $\mathrm{al}^{12}$ found slightly higher plasma concentrations of 17-OHP in normotensives than hypertensive in multivariate analyses of a cross-sectional study. Another cross-sectional study including 321 men subjects suggested that 17-OHP has an inverse association with $\mathrm{BMI}^{26}$ This study represents an extension of prior studies showing a relationship between 17-OHP and MetS. The MetS is a cluster of risk factors (including dyslipidemia, obesity, impaired glucose metabolism, and HTN), and 17-OHP may cause MetS by affecting the occurrence of these factors. We also explored the relationship between 17-OHP and MetS in postmenopausal women, and there is no significant association was found. Thus, our findings suggested that 17-OHP may provide new insights into disease pathophysiology and potential treatment targets in postmenopausal women.

P4 exhibits its function through binding to its related receptors. Accumulating researches have indicated that $\mathrm{P} 4$ is involved in several pathogeneses of obesity, INS resistance, HTN, and dyslipidemia. P4 receptors are expressed in food-related areas outside the hypothalamus, including the caudate, ${ }^{27}$ amygdala, hippocampus, and frontal cortex. ${ }^{28}$ They are also widely distributed in many regions which can mediate pleasure, motivation, and cognition especially in the control of abnormal eating. On the other hand, $\mathrm{P} 4$ receptor membrane-associated component 1 contributes to the development of obesity via lipid accumulation in adipocytes to regulate adipohenesis. ${ }^{29}$ Previous studies also shed light on the expression of glucose transporter 4 could be inhibited by $\mathrm{P} 4,{ }^{30}$ resulting in increased INS resistance, ${ }^{31}$ especially in skeletal muscle and adipose tissue. The different steps of the PI 3-kinase pathway may be inhibited by $\mathrm{P} 4$, resulting in increased INS resistance as well as decreased glucose intake. ${ }^{32}$ Another study further validated the association and suggested that obesity and adiponectin may mediate the relationship between P4 and INS resistance. ${ }^{33}$ What is more, it is possible that progestogens upregulate androgen receptors increase the risk of HTN in susceptible women ${ }^{34}$ and upregulate the thrombin receptor in the vessel wall, increasing the risk of atherosclerotic and thromboembolic disease. ${ }^{35}$ The use of progestin annulled the benefits of atorvastatin on TC, LDL-C and the benefits of estradiol on HDL-c were discovered by a double-blind randomized placebo-controlled study. ${ }^{36}$ So, we infer that $\mathrm{P} 4$ is also related to hypercholesterolemia. On the other hand, however, some findings suggest that hormonal replacement therapy and dietary supplements may affect hormone levels in the body and also influence 
some of the factors that contribute to the development of MetS. $^{37-39}$ This is an exciting finding, but due to the differences in the study populations, the results of the sensitivity analysis showed that these effects did not change our results significantly when the subjects involved in hormone replacement therapy were excluded, and further research is needed to investigate this effect. Taken together, obesity, INS resistance, HTN and HD are the main characteristic of MetS, so we believe P4 had a positive correlation with MetS.

17-OHP is mainly produced by the Leydig cells tested through luteinizing hormone stimulation, and the adrenal glands are responsible for the residual biosynthesis. ${ }^{6,7,40}$ Obesity is correlated with a global impairment of androgen synthesis by the Leydig cell due to alterations in gonadotropin secretion. ${ }^{41}$ Therefore, the concentration of 17-OHP and testosterone could be related to obesity because of the disruption of the hypothalamic-pituitarygonadal axis. Moreover, adrenal synthesis of 17-OHP could be affected in a similar form. 17-OHP is a precursor of testosterone, which is converted to androstenedione by Cytochrome P450 Family 17 Subfamily A Member 1 and then to testosterone by Recombinant 17 Beta-Hydroxysteroid Dehydrogenase Type 3. A clinical trial study observed that after testosterone treatment, the prevalence of MetS was lower in the testicular cancer survivors whose Leydig cell function has gotten compensation. Moreover, a meta-analysis of observational studies showed a negative association of high testosterone on MetS. $^{42}$ Therefore, it may be reasonable that 17-OHP has a negative association with MetS. Hitherto, the specific mechanism underlying the effects of 17-OHP on the MetS is not clear and it requires extensive animal experiments and epidemiological studies. Based on the above analysis, the present study further validated their effects on MetS by analyzing the combined effects of P4 and 17OHP. There is still a need to further evaluate the potential use of progestins in the treatment of metabolic diseases and whether their impact on the body's metabolism should be considered in the context of existing progestin therapy.

The primary strength of this study is that participants of men and postmenopausal women were included to explore the potential gender-specific relationships of P4 and 17-OHP with MetS. We examined not only the dependent relationship of $\mathrm{P} 4$ and 17-OHP but also the combined effects of P4 and 17-OHP on MetS. To the best of our knowledge, the present study hereby for the first time there shows different combined effects of P4 and 17-OHP on MetS among men and postmenopausal women. It showed the combination of a low level of P4 and a high level of 17-OHP concentrations has the lowest odds ratio of developing MetS in men, and the combination of a high level of 17-OHP had the highest odds ratio of developing MetS in postmenopausal women. Moreover, present cross-sectional observations were derived from a large ongoing cohort study and collect information through a standardized protocol by trained workers ensures a wide range of potential confounders were controlled. However, our study also has some limitations. First of all, even if the traditional MetS risk factors have adjusted, the possibility of residual confounders remains. Second, this is a cross-sectional study and cannot be certain the causal associations. Third, the statistic was collected from the Henan rural area, so the results may not be suitable to apply to urban area. Fourth, although an inverse relationship between the concentration of 17-OHP and MetS was observed, the mechanism remains unclear.

\section{Conclusions}

Altogether, the present study found that P4 and 17-OHP may play essential roles in the development of MetS. Given the high prevalence and huge burden of MetS, our findings may have a pivotal influence on public health. Yet, the potential mechanism by which P4 and 17-OHP influence MetS remains to be elucidated and these associations remain to be validated in prospective multicenter studies. In addition, further studies are needed to explore the influence of progestogen receptor function on MetS.

\section{Data Sharing Statement}

The datasets generated during and/or analyzed during the current study are available from the corresponding author on reasonable request.

\section{Ethics Approval and Informed Consent}

The study and its protocols were approved by the Zhengzhou University Life Science Ethics Committee and conducted in compliance with the principles of the Declaration of Helsinki. All participants were informed of the purpose and nature of all procedures used and provided written informed consent. 


\section{Consent for Publication}

The participant has consented to the submission.

\section{Acknowledgments}

The authors would like to thank the research participants for their participation in this study. We also express our gratitude for the research team who worked for the data collection and laboratory measurement.

\section{Author Contributions}

All authors made a significant contribution to the work reported, whether that is in the conception, study design, execution, acquisition of data, analysis and interpretation, or in all these areas; took part in drafting, revising or critically reviewing the article; gave final approval of the version to be published; have agreed on the journal to which the article has been submitted; and agree to be accountable for all aspects of the work.

\section{Funding}

This research was supported by the National Natural Science Foundation of China (Grant NO: 21806146), the National Key Research and Development Program of China (Grant NO: 2016YFC0900803, 2019YFC1710002), the Postdoctoral Science Foundation of China (Grant NO: 2016M602264, 2020T130604), and the Excellent Youth Development Foundation of Zhengzhou University (Grant No: 2018ZDGGJS052), and the Science and Technique Foundation of Henan Province (Grant No: 202102310074).

\section{Disclosure}

The authors declare no conflicts of interest.

\section{References}

1. Geneva S, World Health Organization. Global health estimates 2016: disease burden by cause, age, sex, by country and by region, 20002016; 2018. Available from: http://www.who.int/healthinfo/global_bur den_disease/en/. Accessed October 4, 2021.

2. Lu J, Wang L, Li M, et al. Metabolic syndrome among adults in China: the 2010 China noncommunicable disease surveillance. J Clin Endocrinol Metab. 2017;102(2):507-515. doi:10.1210/jc.2016-2477

3. Scholze J, Alegria E, Ferri C, et al. Epidemiological and economic burden of metabolic syndrome and its consequences in patients with hypertension in Germany, Spain and Italy; a prevalence-based model. BMC Public Health. 2010;10:529. doi:10.1186/1471-2458-10-529

4. Pothiwala P, Jain SK, Yaturu S. Metabolic syndrome and cancer. Metab Syndr Relat Disord. 2009;7(4):279-288. doi:10.1089/ met.2008.0065

5. Hydroxyprogesterone $\mid \mathrm{C} 21 \mathrm{H} 30 \mathrm{O} 3-\mathrm{PubChem} ; 2021$. Available from: https://pubchem.ncbi.nlm.nih.gov/compound/hydroxyprogesterone. Accessed October 4, 2021.
6. Stege R, Eriksson A, Henriksson P, Carlström K. Orchidectomy or oestrogen treatment in prostatic cancer: effects on serum levels of adrenal androgens and related steroids. Int $J$ Androl. 1987;10(4):581-587. doi:10.1111/j.1365-2605.1987.tb00357.x

7. Carlström K, Stege R. Adrenocortical function in prostatic cancer patients: effects of orchidectomy or different modes of estrogen treatment on basal steroid levels and on the response to exogenous adrenocorticotropic hormone. Urol Int. 1990;45(3):160-163. doi: 10.1159/000281699

8. Hofmann A, Peitzsch M, Brunssen C, et al. Elevated steroid hormone production in the $\mathrm{db} / \mathrm{db}$ mouse model of obesity and type 2 diabetes. Horm Metab Res. 2017;49(1):43-49. doi:10.1055/s-0042-116157

9. Newell-Fugate AE, Taibl JN, Alloosh M, et al. Effects of obesity and metabolic syndrome on steroidogenesis and folliculogenesis in the female Ossabaw mini-pig. PLoS One. 2015;10(6):e0128749. doi:10.1371/journal.pone.0128749

10. Jiang J, Liu X, Liu X, et al. The effect of progesterone and pregnenolone on diabetes status in Chinese rural population: a dose-response analysis from Henan Rural Cohort. Eur $J$ Endocrinol. 2019;181(6):603-614. doi:10.1530/EJE-19-0352

11. Stachenfeld NS. Hormonal changes during menopause and the impact on fluid regulation. Reprod Sci. 2014;21(5):555-561. doi:10.1177/1933719113518992

12. Eisenhofer G, Peitzsch M, Kaden D, et al. Reference intervals for plasma concentrations of adrenal steroids measured by LC-MS/MS: impact of gender, age, oral contraceptives, body mass index and blood pressure status. Clin Chim Acta. 2017;470:115-124. doi:10.1016/j.cca.2017.05.002

13. Page ST, Krauss RM, Gross C, et al. Impact of mifepristone, a glucocorticoid/progesterone antagonist, on HDL cholesterol, HDL particle concentration, and HDL function. $J$ Clin Endocrinol Metab. 2012;97(5):1598-1605. doi:10.1210/jc.2011-2813

14. Liu X, Mao Z, Li Y, et al. Cohort Profile: the Henan Rural Cohort: a prospective study of chronic non-communicable diseases. Int J Epidemiol. 2019;48(6):1756-1756j. doi:10.1093/ ije/dyz039

15. Fan M, Lyu J, He P. [Chinese guidelines for data processing and analysis concerning the International Physical Activity Questionnaire]. Zhonghua Liu Xing Bing Xue Za Zhi. 2014;35 (8):961-964. Chinese.

16. Sun X, Li J, Jin S, et al. Associations between repeated measures of maternal urinary phthalate metabolites during pregnancy and cord blood glucocorticoids. Environ Int. 2018;121(Pt 1):471-479. doi:10.1016/j.envint.2018.09.037

17. Liu X, Jiang J, Liu X, et al. Association of serum testosterone with different classes of glucose metabolism and the mediation effect of obesity: the Henan Rural Cohort Study. Diabetes Metab Res Rev. 2019;35(5):e3133. doi:10.1002/dmrr.3133

18. Choi KM, Kim SM, Kim Y-E, Choi DS, Baik SH, Lee J. Prevalence and cardiovascular disease risk of the metabolic syndrome using National Cholesterol Education Program and International Diabetes Federation definitions in the Korean population. Metabolism. 2007;56 (4):552-558. doi:10.1016/j.metabol.2006.12.003

19. Li XT, Liao W, Yu HJ, et al. Combined effects of fruit and vegetables intake and physical activity on the risk of metabolic syndrome among Chinese adults. PLoS One. 2017;12(11):e0188533. doi:10.1371/journal.pone. 0188533

20. Blanchette S, Blouin K, Richard C, Dupont P, Luu-The V, Tchernof A. Expression and activity of 20alpha-hydroxysteroid dehydrogenase (AKR1C1) in abdominal subcutaneous and omental adipose tissue in women. $J$ Clin Endocrinol Metab. 2005;90 (1):264-270. doi:10.1210/jc.2004-0583

21. Blanchette S, Marceau P, Biron S, Brochu G, Tchernof A. Circulating progesterone and obesity in men. Horm Metab Res. 2006;38 (5):330-335. doi:10.1055/s-2006-925392 
22. Hung WC, Ling XH, Chang CC, et al. Inhibitory effects of siegesbeckia orientalis extracts on advanced glycation end product formation and key enzymes related to metabolic syndrome. Molecules. 2017;22(10):1785. doi:10.3390/molecules22101785

23. Levanovich PE, Diaczok A, Rossi NF. Clinical and molecular perspectives of monogenic hypertension. Curr Hypertens Rev. 2020;16 (2):91-107. doi:10.2174/1573402115666190409115330

24. Roelfsema F, Yang RJ, Veldhuis JD. Differential effects of estradiol and progesterone on cardiovascular risk factors in postmenopausal women. J Endocr Soc. 2018;2(7):794-805. doi:10.1210/js.201800073

25. Damgaard-Olesen A, Johannsen TH, Holmboe SA, et al. Reference ranges of 17-hydroxyprogesterone, DHEA, DHEAS, androstenedione, total and free testosterone determined by TurboFlow-LC-MS /MS and associations to health markers in 304 men. Clin Chim Acta. 2016;454:82-88. doi:10.1016/j.cca.2015.12.042

26. Mezzullo M, Di Dalmazi G, Fazzini A, et al. Impact of age, body weight and metabolic risk factors on steroid reference intervals in men. Eur J Endocrinol. 2020;182(5):459-471. doi:10.1530/eje-19-0928

27. Zhu Y, Bond J, Thomas P. Identification, classification, and partial characterization of genes in humans and other vertebrates homologous to a fish membrane progestin receptor. Proc Natl Acad Sci U S A. 2003;100(5):2237-2242. doi:10.1073/pnas.0436133100

28. Brinton RD, Thompson RF, Foy MR, et al. Progesterone receptors: form and function in brain. Front Neuroendocrinol. 2008;29 (2):313-339. doi:10.1016/j.yfrne.2008.02.001

29. Furuhata R, Kabe Y, Kanai A, et al. Progesterone receptor membrane associated component 1 enhances obesity progression in mice by facilitating lipid accumulation in adipocytes. Commun Biol. 2020;3 (1):479. doi:10.1038/s42003-020-01202-x

30. Sugaya A, Sugiyama T, Yanase S, Shen -X-X, Minoura H, Toyoda N. Expression of glucose transporter 4 mRNA in adipose tissue- and skeletal muscle of ovariectomized rats treated with sex steroid hormones. Life Sci. 2000;66(7):641-648. doi:10.1016/s00243205(99)00636-0

31. Butte NF. Carbohydrate and lipid metabolism in pregnancy: normal compared with gestational diabetes mellitus. Am J Clin Nutr. 2000;71 (5Suppl):1256s-1261s. doi:10.1093/ajen/71.5.1256s

32. Wada T, Hori S, Sugiyama M, et al. Progesterone inhibits glucose uptake by affecting diverse steps of insulin signaling in 3T3-L1 adipocytes. Am J Physiol Endocrinol Metab. 2010;298(4):E881-8. doi:10.1152/ajpendo.00649.2009
33. Leung $\mathrm{KC}, \mathrm{Xu} \mathrm{A}$, Craig ME, Martin A, Lam KS, O’Sullivan AJ. Adiponectin isoform distribution in women-relationship to female sex steroids and insulin sensitivity. Metabolism. 2009;58 (2):239-245. doi:10.1016/j.metabol.2008.09.020

34. Hapgood JP, Africander D, Louw R, Ray RM, Rohwer JM. Potency of progestogens used in hormonal therapy: toward understanding differential actions. J Steroid Biochem Mol Biol. 2014;142:39-47. doi:10.1016/j.jsbmb.2013.08.001

35. Kuhl H. Mechanisms of sex steroids. Future developments. Maturitas. 2004;47(4):285-291. doi:10.1016/j.maturitas.2003.11.010

36. Faludi AA, Aldrighi JM, Bertolami MC, et al. Progesterone abolishes estrogen and/or atorvastatin endothelium dependent vasodilatory effects. Atherosclerosis. 2004;177(1):89-96. doi:10.1016/j. atherosclerosis.2004.05.030

37. Găman MA, Dobrică EC, Cozma MA, et al. Crosstalk of magnesium and serum lipids in dyslipidemia and associated disorders: a systematic review. Nutrients. 2021;13(5):1411. doi:10.3390/ nu13051411

38. Zhu Y, Qiu L, Jiang F, et al. The effect of dehydroepiandrosterone (DHEA) supplementation on estradiol levels in women: a dose-response and meta-analysis of randomized clinical trials. Steroids. 2021;173:108889. doi:10.1016/j.steroids.2021.108889

39. Yang F, Li N, Gaman MA, Wang N. Raloxifene has favorable effects on the lipid profile in women explaining its beneficial effect on cardiovascular risk: a meta-analysis of randomized controlled trials. Pharmacol Res. 2021;166:105512. doi:10.1016/j.phrs.2021.105512

40. Tchernof A, Després JP, Bélanger A, et al. Reduced testosterone and adrenal C19 steroid levels in obese men. Metabolism. 1995;44 (4):513-519. doi:10.1016/0026-0495(95)90060-8

41. Kokkoris P, Pi-Sunyer FX. Obesity and endocrine disease. Endocrinol Metab Clin North Am. 2003;32(4):895-914. doi:10.1016/s0889-8529(03)00078-1

42. Brand JS, Rovers MM, Yeap BB, et al. Testosterone, sex hormone-binding globulin and the metabolic syndrome in men: an individual participant data meta-analysis of observational studies. PLoS One. 2014;9(7):e100409. doi:10.1371/journal. pone.0100409

\section{Publish your work in this journal}

Diabetes, Metabolic Syndrome and Obesity: Targets and Therapy is an international, peer-reviewed open-access journal committed to the rapid publication of the latest laboratory and clinical findings in the fields of diabetes, metabolic syndrome and obesity research. Original research, review, case reports, hypothesis formation, expert opinion and commentaries are all considered for publication. The manuscript management system is completely online and includes a very quick and fair peer-review system, which is all easy to use. Visit http://www.dovepress.com/testimonials.php to read real quotes from published authors. 